\title{
Print-Light-Synthesis of Platinum Nanostructured Indium-Tin-Oxide Electrodes for Energy Research
}

\section{Andreas Lesch} nanoparticles and structures on large substrates. Here, Pt nanoparticles are synthesized on indium tin oxide (ITO) coated glass slides by using combined inkjet printing and photonic curing operated under ambient conditions and with low material usage. A formulated chloroplatinic acid based ink provides stable and reproducible jetting, optimized ink-substrate interaction and fast ink drying to create well-defined thin precursor films acting as nanoreactors. The precursor loading is precisely controlled by the printing parameters. Then, a short light pulse from a Xe flash lamp fully converts the printed Pt precursor containing film into pure Pt nanoparticles. The optimum precursor coverage is $\approx 1 \mu \mathrm{g} \mathrm{mm}^{-2} \mathrm{Pt}$ consuming as less as $\approx 50 \mathrm{~nL} \mathrm{~mm} \mathrm{~mm}^{-2}$ of ink. Neither reducing nor capping agents are used resulting in pure $\mathrm{Pt}$ nanoparticles ( $30 \mathrm{~nm}$ average size) and micrometer-size aggregates. The nanostructures are well-adhered to the ITO substrate and show a stable electrochemical performance for the oxygen reduction reaction. The fast and cost-effective process optimization in terms of ink formulation, substrate pre-treatment, inkjet printing resolution, and post-processing for the rapid fabrication of $\mathrm{Pt}$ nanoand microparticle-coated ITO electrodes is presented and discussed.
Print-light-synthesis is a new concept for the large-scale in situ fabrication of

effects with conductive support materials, such as carbon black, boron carbide $\left(\mathrm{B}_{4} \mathrm{C}\right)$, antimony tin oxide (ATO), titanium dioxide $\left(\mathrm{TiO}_{2}\right)$, or indium tin oxide (ITO), are of major importance for the catalytic activity, stability, and sensitivity of the Ptbased nanoparticles (NPs) and require accurate design and syntheses strategies. ${ }^{[3]}$ Typically, catalyst precursors are employed that are chemically or thermally reduced into the metallic NPs. Solvothermal synthesis, thermal decomposition, sol-gel method, electrochemical or electroless deposition are among the most popular fabrication routes whereas the application of microwave, UV light, or laser-assisted methods is less frequent. ${ }^{[4]}$ Generally, the syntheses require well-defined process conditions, such as pressure, temperature, purity, and time. Wet NP syntheses need capping agents that control and limit the NP growth, but that easily remain on the NPs due to strong adsorption. Without specific post-treatment, it can lead to the

\section{Introduction}

Low-cost, large-scale production of functional nanomaterials is of large interest for a broad range of applications ranging from bioanalytical sensing to energy conversion systems. This concerns the screening for new functional nanomaterials and structures, as well as the production of devices. For instance, electrochemical energy conversion devices, such as polymer electrolyte membrane fuel cells (PEMFCs) and electrolyzers, will play an important role, for instance, in electromobility, where the former generates electrical energy from hydrogen that is produced on demand by the latter. ${ }^{[1]}$ In such devices, Pt and Pt alloys act as electrocatalysts and are still without real economic and functional alternative for the hydrogen oxidation reaction (HOR), hydrogen evolution reaction (HER), and the oxygen reduction reaction (ORR). ${ }^{[2]}$ The catalyst material properties, such as size, shape, composition, and synergistic

\section{Dr. A. Lesch}

École Polytechnique Fédérale de Lausanne

Laboratory of Physical and Analytical Electrochemistry

EPFL Valais Wallis

rue de l'Industrie 17, Case Postale 440, CH-1951 Sion, Switzerland

E-mail: andreas.lesch@epfl.ch

The ORCID identification number(s) for the author(s) of this article can be found under https://doi.org/10.1002/admt.201700201.

DOI: 10.1002/admt.201700201 alteration of the catalytic activity. While many efforts are being made to design, characterize, and optimize nanostructured catalysts, ${ }^{[5]}$ the upscaling of a successful lab-scale synthesis to the industrial production level remains challenging and requires advanced material deposition techniques guaranteeing high accuracy, reproducibility, and flexibility. In various approaches, the NPs or supported NPs are first dispersed, partially together with stabilizing agents, forming a paste that is then transferred onto a support layer using, for instance, drop-casting, screenprinting, ${ }^{[6]}$ or electrospraying. ${ }^{[7]}$

Recently, digital material deposition techniques, such as drop-on demand inkjet printing with piezoelectric or thermally driven printheads, have opened new opportunities for process design and development. ${ }^{[8]}$ Stable inks result in very reproducible droplets of picoliter volume that can be jetted with frequencies ranging from the lower $\mathrm{Hz}$ to the $\mathrm{kHz}$ range. The achievable printing resolution is determined by the droplet volume and the ink-substrate interaction, which generally results in deposited droplets as small as $30-50 \mu \mathrm{m}$ in diameter. Inkjet printing can be operated with nanoparticulate dispersions but also with dissolved precursor inks. After droplet deposition, the printed film is post-processed by using, for example, thermal and/or (photo)chemical methods to convert the ink into a solid functional layer through sintering or a (photo) chemical reaction. The latter approach is often termed reactive inkjet printing. ${ }^{[9]}$ Parallel printheads with up to several hundred nozzles and integrated post-processing techniques, such 


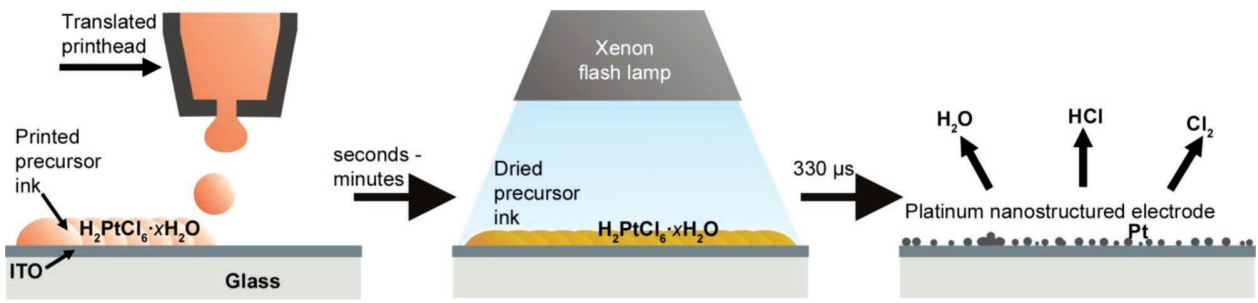

Scheme 1. Schematic representation of the combined inkjet printing and photonic curing process to fabricate platinum nanostructures on an ITO electrode.

as UV-photopolymerization enable full process control and automation, and can reduce the costs for research and development, as well as large-scale production. ${ }^{[10]}$

Inkjet printing can be applied for both the characterization of new electrocatalyst materials and the production of catalyst layers. It has recently been employed by various groups to print catalyst layers for PEMFCs composed of carbon black supported Pt nanoparticles and an ionomer. ${ }^{[11]}$ The electrocatalyst nanoparticles and the ionomer are generally dispersed in the ink and printed from a single printhead. Alternatively, by using two parallel printheads, from which one is loaded with a pure ionomer ink, or by printing subsequently a pure ionomer ink the electrocatalyst/ionomer ratio can conveniently be adjusted. ${ }^{[12]}$ However, a successful inkjet printing process depends strongly on the physicochemical ink properties, mainly viscosity and surface tension, but also on the ink stability. Working with nanoparticulate dispersions is challenging, because NPs can agglomerate and precipitate causing serious issues with nozzle clogging. On the contrary, precursor inks do not only lower significantly the risk of nozzle blocking but also show the major advantage of making a prior NP synthesis obsolete. With parallel printheads also combinatorial electrocatalyst libraries can be printed and subsequently screened for their catalytic performance using various established electrochemical and spectroscopic analytical techniques. ${ }^{[13]}$ Typically, the conversion of $\mathrm{Pt}$ precursors into Pt metal is achieved by thermal decomposition or thermally induced reduction in a furnace, which can be time consuming. Alternatively, ambient post-processing techniques, such as photonic curing (also known as flash light annealing or intense pulsed light sintering), can induce thermal post-processing reaching various hundred degrees within a fraction of a second. ${ }^{[14]}$ A flash lamp can irradiate with several $\mathrm{J} \mathrm{cm}^{-2}$ a substrate coated with a thin layer of nanoparticles, molecules, or precursor salts that depending on their optical properties absorb the light and can heat up to several hundred degrees within a fraction of a second causing a rapid thermally induced process, such as sintering or thermal decomposition. Alternatively, solid nanostructures, such as carbon nanotubes or $\mathrm{Cu}$ NPs, can absorb the light, increase the surface temperature, and transfer the heat to surrounding precursors. Transparent substrates or substrates with poorly absorbing light properties can be unaffected, which represents a great advantage for lowtemperature substrates such as polymers. Photonic curing is mainly used with the goal to create homogeneous and compact conductive films from nanoparticles and precursors, such as $\mathrm{Cu}^{[15]}$ or $\mathrm{Ag},{ }^{[16]}$ but rarely for separate nanoparticles as applied for analytical and catalytic applications. Recently, Kim and coworkers used metal, metal alloy, and metal oxide precursors on carbonaceous substrates. ${ }^{[17]}$ However, the starting compounds were supported on materials that possibly absorb the flash lamp light stronger than the precursors for the applied pulse times of up to $15 \mathrm{~ms}$.

Herein, the rapid fabrication of Pt nano- and microstructures on ITO glass slides by combining efficiently inkjet printing (i.e., few minutes including ink drying time) and photonic curing (i.e., only $330 \mu \mathrm{s}$ ) of a chloroplatinic acid containing ink is presented (Scheme 1) to prepare 2D electrode patterns that can potentially be used for catalyst screening or in devices requiring Pt NP-decorated electrodes. The precursor film is absorbing the light and subsequently converted into the metal. Inkjet printing has been chosen to deposit various precursor loadings with high precision in order to identify the film properties for a successful photonic curing process. ITO has been selected because it has been shown to be a promising support material for Pt nanoparticles thanks to its higher stability against corrosion compared to Vulcan XC-72. ${ }^{[3 \mathrm{~b}]}$ Alternative fabrication routes for Pt/ITO particles and films are broad and include electrochemical deposition, ${ }^{[18]}$ chemical reduction, ${ }^{[19]}$ ultrahigh vacuum techniques, ${ }^{[20]}$ thermal decomposition, ${ }^{[21]}$ galvanostatic displacement of $\mathrm{Cu}^{\left[{ }^{[22]}\right.}$ and nitrogen plasma. ${ }^{[23]}$ Furthermore, thin Pt layers on ITO glass are frequently used as catalytically active material on counter electrodes in dye-sensitized solar cells (DSSCs), in which Pt loadings below $3 \mu \mathrm{g} \mathrm{cm}^{-2}$ resulted in transparent catalyst films. ${ }^{[24]}$ In addition, the ITO-coated glass slides are stable during the optimized photonic curing process. No changes in morphology and conductivity were detected.

The ink volumes applied in this work for square millimeter sized areas were in the lower $\mathrm{nL}$ range demonstrating the cost-effectiveness of the photonic curing assisted printsynthesis for fast development and production. Both surface tension and viscosity of the ink were adjusted for high-resolution printing and to achieve suitably fast ink drying times for rapid post-processing. The influences of the precursor loading and photonic curing parameters on the Pt formation are discussed. The inkjet-printed Pt/ITO electrodes were characterized by scanning electron microscopy (SEM), energy-dispersive X-ray (EDX) spectroscopy, X-ray diffraction (XRD), X-ray photoelectron spectroscopy (XPS), and voltammetry. The last was extended to explore the activity of the Pt nanoparticles for the ORR.

\section{Results and Discussion}

A successful inkjet printing process is linked to the proper adjustment of (i) the physicochemical properties of the ink (mainly viscosity, surface tension, and solubility/dispersibility 
of the material to be printed), (ii) printing parameters (e.g., piezoelectric actuation), (iii) ink-substrate interaction (wetting behavior), and (iv) post-processing (to convert the ink after drying into a solid functional material). A ternary solvent mixture of water, isopropanol, and 1,2-propanediol was identified in this work as the ideal carrier for the Pt precursor ink and for printing with high resolution on the ITO-coated glass slides. In fact, $50 \mathrm{mg}$ of the Pt precursor $\mathrm{H}_{2} \mathrm{PtCl}_{6} \cdot x \mathrm{H}_{2} \mathrm{O}$ could be dissolved in $1 \mathrm{~mL}$ of the ink. The jettability of an ink can be characterized by using the Ohnesorge number. ${ }^{[25]}$ The reciprocal of the Ohnesorge number is termed $Z$-value, which is defined as $Z=1 / O h=\sqrt{(\gamma \rho a)} / \eta$ where $\gamma, \eta$, and $\rho$ are the surface tension, viscosity, and density of the ink, respectively, whereas $a$ represents a characteristic length (here the nozzle diameter with $a=21.5 \mu \mathrm{m}$ ). The ternary solvent mixture applied herein was identified as the ideal carrier for the Pt precursor ink: water to facilitate precursor dissolution, isopropanol to adjust $\gamma$ and 1,2-propanediol to adjust both $\eta$ and the drying time of the printed ink film. A $Z$ value of 5.6 was achieved, which is well placed inside the printable range of $1<Z<10 .{ }^{[25]}$ In fact, stable jetting of $\approx 17.3 \mathrm{pL}$ droplets was obtained (Figure 1a) by applying a custom designed voltage signal to the piezoelectric actuators of the printhead (Section SI-1, Supporting Information). Achieving stable and reproducible droplets is essential for inkjet printing, because it enables the highly reproducible production of well-defined thin layers of known composition, such as an array of separated droplets (Figure 1b). Purging of the nozzles, a standard procedure when using nanoparticulate inks to free nozzles from clogging, was not required leading to a real drop-on-demand ink deposition process without any ink waste.

The Pt precursor ink developed herein showed a good wetting behavior over the ITO substrate when squared areas of $1 \mathrm{~mm}^{2}$ (pattern design) were printed each with 3050 droplets $(\approx 1400$ dpi). Printing one of such patterns with eight parallel nozzles and $1 \mathrm{kHz}$ jetting frequency took only $1 \mathrm{~min}$ and required as few as $52.8 \mathrm{~nL}$ of ink containing $1.03 \mu \mathrm{g}$ of Pt. Directly after the deposition on the ITO glass, the printed liquid film appeared almost transparent (Figure 1c, left, guides to the eye in Section SI-2, Supporting Information). Due to presence of 1,2-propanediol (vapor pressure $0.08 \mathrm{~mm} \mathrm{Hg}\left(20^{\circ} \mathrm{C}\right.$ ) as given by the manufacturer), the overall ink evaporation rate was slow enough to avoid the formation of a large amount of precipitated Pt salt on the ITO surface, but fast enough to result within 5-10 min after printing into a thin homogeneous liquid film (Figure 1c, middle). The color of the printed film turned stronger to yellow and the shape of the patterns appeared more defined in the grayscale image recorded from the fabrication analyzer camera of the printer. The droplet drying behavior at the printing temperature was precisely analyzed using a drop shape analyzer where the substrate holder plate was replaced by a Peltier element for precise temperature control (Section SI-3, Supporting Information). The importance of the thickness of the slightly dried precursor film is given by the fact that an excess of residual ink carrier, that is, a quite diluted precursor ink, results on the one hand in a poor light absorption and on the other hand in a cooling effect for the desired thermal process induced by photonic curing.

During slow equilibrium heating in a furnace at air chloroplatinic acid decomposes fully into $\mathrm{Pt}, \mathrm{H}_{2} \mathrm{O}, \mathrm{HCl}$, and $\mathrm{Cl}_{2}$ at a)
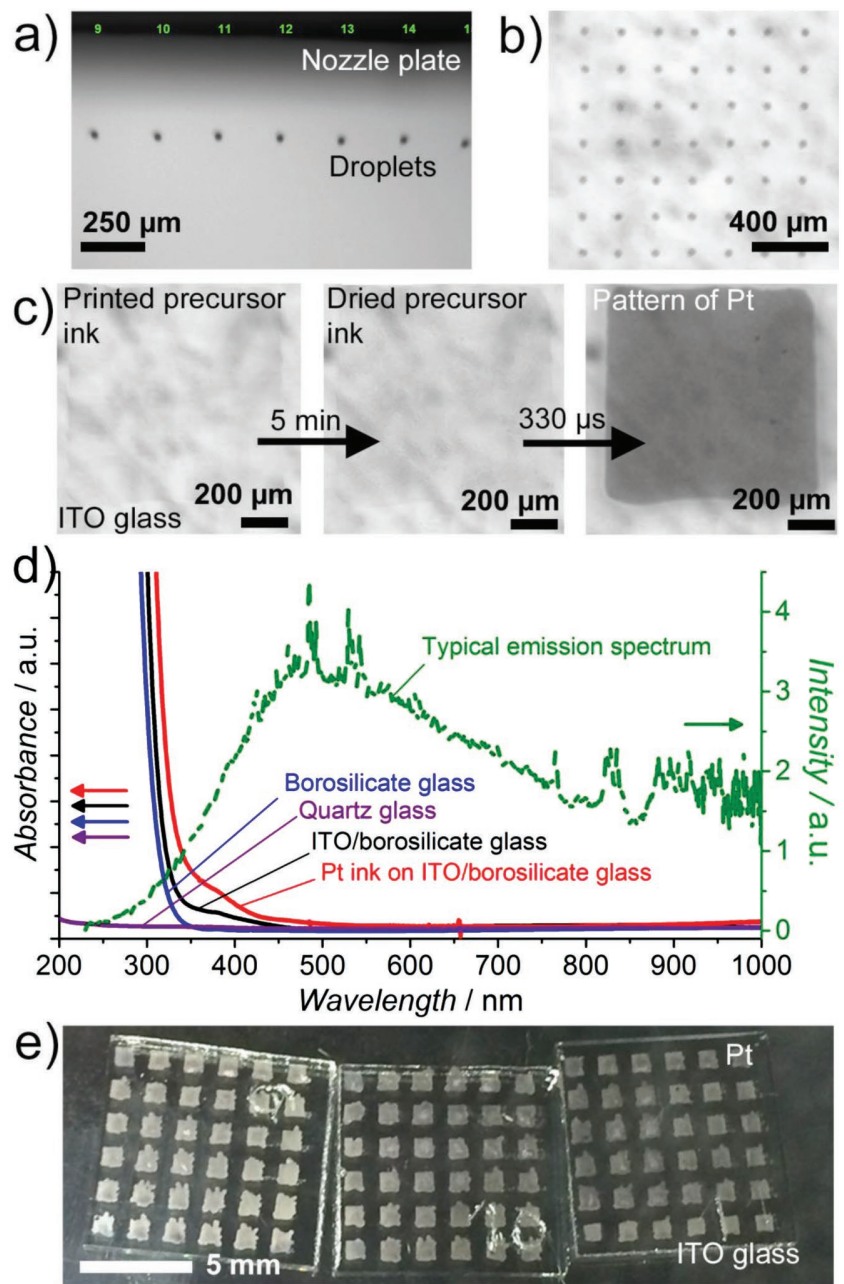

f)

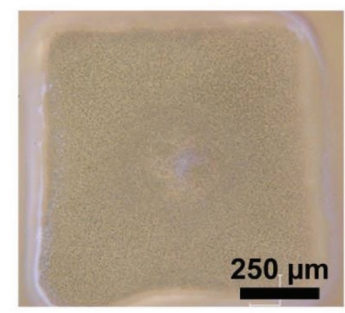

g)

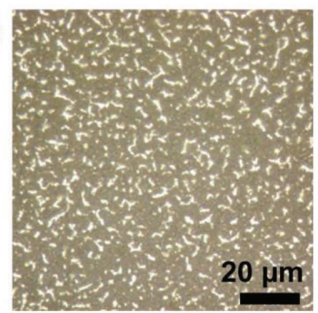

Figure 1. a) Droplets generated from seven exemplary parallel nozzles. b) Printed droplet array. c) Printed Pt precursor square of $1 \mathrm{~mm}^{2}$ recorded with the printer fabrication analyzer camera directly after printing (left), after 5 min drying at $54{ }^{\circ} \mathrm{C}$ (center) and after photonic curing using a $330 \mu \mathrm{s}$ short pulse with $(3.52 \pm 0.03) \mathrm{J} \mathrm{cm}^{-2}$ shot energy density (right). Please note that the grayish shadows in the image background show the metallic substrate plate of the printer which can be seen through the fully transparent ITO glass substrate and through the printed pattern. d) Absorption spectra of bare borosilicate glass slide (blue), ITO glass slide (black), Pt ink on ITO glass slide (red), and nonabsorbing quartz glass (violet) prior to photonic curing (750 V for $200 \mu \mathrm{s}$, emission spectrum in green). e) 108 reproducible Pt patterns on three ITO glass slides, each $1.25 \times 1.25 \mathrm{~cm}^{2}$ in size. $f, g)$ Optical microscopy images of a photonic cured Pt pattern.

temperatures exceeding $500{ }^{\circ} \mathrm{C}$ (Section SI-4, Supporting Information). ${ }^{[26]}$ This temperature threshold will only be exceeded by light if (i) the printed film absorbs enough light to be heated-up or (ii) the substrate absorbs the light and generates a local heat 
on its surface that is then rapidly transferred to the precursor layer. It has to be noted that chloroplatinic acid is less often used for the synthesis of Pt NPs by thermal decomposition under equilibrium conditions than, for instance, platinum acetylacetonate $\left(\mathrm{Pt}(\mathrm{acac})_{2}\right)$, which has a lower thermal decomposition temperature and can lead to small NPs with very narrow size distribution. However, $\mathrm{Pt}(\mathrm{acac})_{2}$ is not soluble in the ink composition developed herein for high-resolution printing with accelerated solvent evaporation on the ITO-coated substrates. From the printed thin chloroplatinic acid containing layer, $\mathrm{Pt}$ was generated using a single pulse as short as $330 \mu$ s with a shot energy density of $(3.52 \pm 0.03) \mathrm{J} \mathrm{cm}^{-2}$ (Figure $1 \mathrm{c}$, right). The absorption spectra of thin films deposited on ITO and quartz-glass were compared with the broad emission spectrum of the Xe flash lamp (Figure 1d). At $300 \mathrm{~nm}$, the energy delivered to the substrate is $\approx 0.5 \mathrm{~J} \mathrm{~cm}^{-2}$ and exceeds $3 \mathrm{~J} \mathrm{~cm}^{-2}$ at $500 \mathrm{~nm}$. Poor light absorbing materials, such as quartz glass, show negligible absorption (i.e., no temperature increase of the quartz) and represent ideal substrates for investigating the mechanism of the flash light initiated precursor absorption and conversion processes. In fact, a solid, conductive gray pattern (shiny under a light microscope) was created using the same pulse suggesting a direct conversion process in which the $\mathrm{Pt}$ thin precursor film absorbed the light and heated up to more than $500{ }^{\circ} \mathrm{C}$ (Section SI-5, Supporting Information). Borosilicate glass shows weak light absorption above $300 \mathrm{~nm}$. Borosilicate glass coated with a nanolayer of ITO results in a small shoulder for the absorption at $380 \mathrm{~nm}$. However, when covered with a Pt precursor ink the absorbance is shifted toward larger wavelengths and shows an enhanced absorption until more than $500 \mathrm{~nm}$ due to the presence of the Pt precursor. Simulation results suggest that the ITO film heats up to $375{ }^{\circ} \mathrm{C}$ only with the pulses applied herein (Section SI-6, Supporting Information). Hence, the ITO layer might support the temperature increase, but the optical properties of the Pt precursor ink predominate to overcome the required thermal decomposition temperature for the formation of Pt. Wet synthesis approaches under UV light irradiation for Pt NPs in solution are often carried out in the presence of alcohols with reducing properties, but a long lasting process of up to several hours, which is influenced and accelerated by the subsequent formation of $\mathrm{Pt}$ chlorides and Pt clusters. ${ }^{[27]}$ Since also the photonic curing light contains UV, it could be possible that such nucleation sites are immediately formed in the print-light-synthesis enhancing the formation of the Pt nanostructures with a positive effect on the temperature increase. However, the presence or absence of alcohols in the Pt precursor ink did not influence the formation of the Pt nanostructures by photonic curing in this work (Section SI-7, Supporting Information).

The obtained Pt patterns appeared homogeneous and mainly as well-defined squares that stayed on the ITO substrate after rinsing with deionized (DI) water and drying with a stream of nitrogen (Figure 1e). ITO is a challenging surface for printing and can result in lateral pattern shrinkage during ink drying. In such case, the flat and squared ink pattern contracts toward the center of the printed pattern in case of a mismatch of ink surface tension and surface free energy of the substrate. Such effect was almost completely suppressed by the applied ITO pre-treatment, while untreated ITO showed a poor printing resolution. In fact, the real Pt pattern size was $\approx 0.94 \mathrm{~mm}^{2}$ due to the minor shrinkage during drying. Only at the contour of the printed pattern the film thickness appeared a bit thinner (Figure 1f and vide infra). Increasing the surface free energy excessively, for example, by using oxygen plasma, resulted in an uncontrolled wetting where the ink spread all over the ITO surface (Section SI-8, Supporting Information). The measured contact angle of the Pt precursor ink on the pre-treated ITO glass substrate was $(43.05 \pm 1.23)^{\circ}$.

The Pt patterns were composed of nanoparticles and their aggregates as it can be seen in optical microscopy images (Figure 1g) and SEM images (Figure 2a-c). Nearly spherical nanoparticles with an average size of $30.1 \mathrm{~nm}$ and a surface coverage of $13 \%$ (Section SI-9, Supporting Information) are accompanied by larger aggregates of micrometer size. The shape and the size distribution of both the larger and the smaller particles were homogeneous over the entire surface. The larger particles could be the result of sintered smaller particles that probably folded together. Alternatively, larger crystals, if already present in the slightly dried ink, could have split during the thermal decomposition (Section SI-10, Supporting Information). This could be the result of the rapid gas evolution as indicated by some craters in the centers of the larger particles (Figure 2a). In fact, Pt salt crystals or initially formed $\mathrm{Pt}$ atoms could have acted as nucleation sites (Section SI-10, Supporting Information).

Platinum and chlorine were clearly present and identically distributed in the noncured sample as observed by EDX spectroscopy (Figure 3a,c). After photonic curing, the EDX Pt map and spectra show a clear Pt distribution while the chlorine signal completely diminished from the major part of the printed pattern due to its successful removal (Figure 3b,d). Only at the rim of the printed film the Pt precursor conversion was incomplete as a result of an inverse coffee-ring effect with lower Pt precursor loading causing less efficient light absorption (vide infra). The XRD spectrum (Figure 3e) shows four characteristic peaks for the according Pt faces at diffraction angles: $39.87^{\circ}(111)$, $46.37^{\circ}(200), 67.61^{\circ}(200)$, and $81.46^{\circ}(311)$. No peaks related to the Pt precursor were found and the lattice constant equal to $(3.923 \pm 0.002) \AA$ was consistent with literature. The mean isotropic domain size was refined to $(62 \pm 3) \mathrm{nm}$ (Section SI-9, Supporting Information). This correlates with the observations from the SEM analysis, considering that the smaller particles do not contribute much to the XRD signals and larger particles did not broaden the obtained peaks due to the available XRD resolution. The XPS spectrum (Figure $3 \mathrm{f}$ ) shows in the $\mathrm{Pt} 4 \mathrm{f}$ region a clear peak for Pt $4 \mathrm{f} 7 / 2$ (Pt 4f5/2) at $70.4 \mathrm{eV}(73.69 \mathrm{eV}$, $\Delta=3.29 \mathrm{eV})$. In literature, the location of the $\mathrm{Pt} 4 \mathrm{f} 7 / 2$ peak for metallic Pt is given as $71.2 \mathrm{eV}$ with a $\Delta$ of $3.33 \mathrm{eV}$ while for platinum chlorides and also oxides the $\mathrm{Pt} 4 \mathrm{f} 7 / 2$ peak is shifted toward higher binding energies. This confirms on the one hand that the conversion of the Pt precursor into Pt took place and on the other hand that no durable oxidation to $\mathrm{PtO}_{\mathrm{x}}$ occurred during the photonic curing process. Most importantly, no $\mathrm{Cl}$ $2 \mathrm{p} 3 / 2(\mathrm{Cl} 2 \mathrm{p} 1 / 2)$ peak was detected at its typical position of $198.5 \mathrm{eV}(200.1 \mathrm{eV})$. $^{[28]}$

Importantly, the synthesis of the $\mathrm{Pt}$ nanostructures by photonic curing is determined by the precursor coverage and flash light intensity (Figure 4). A precursor coverage of 

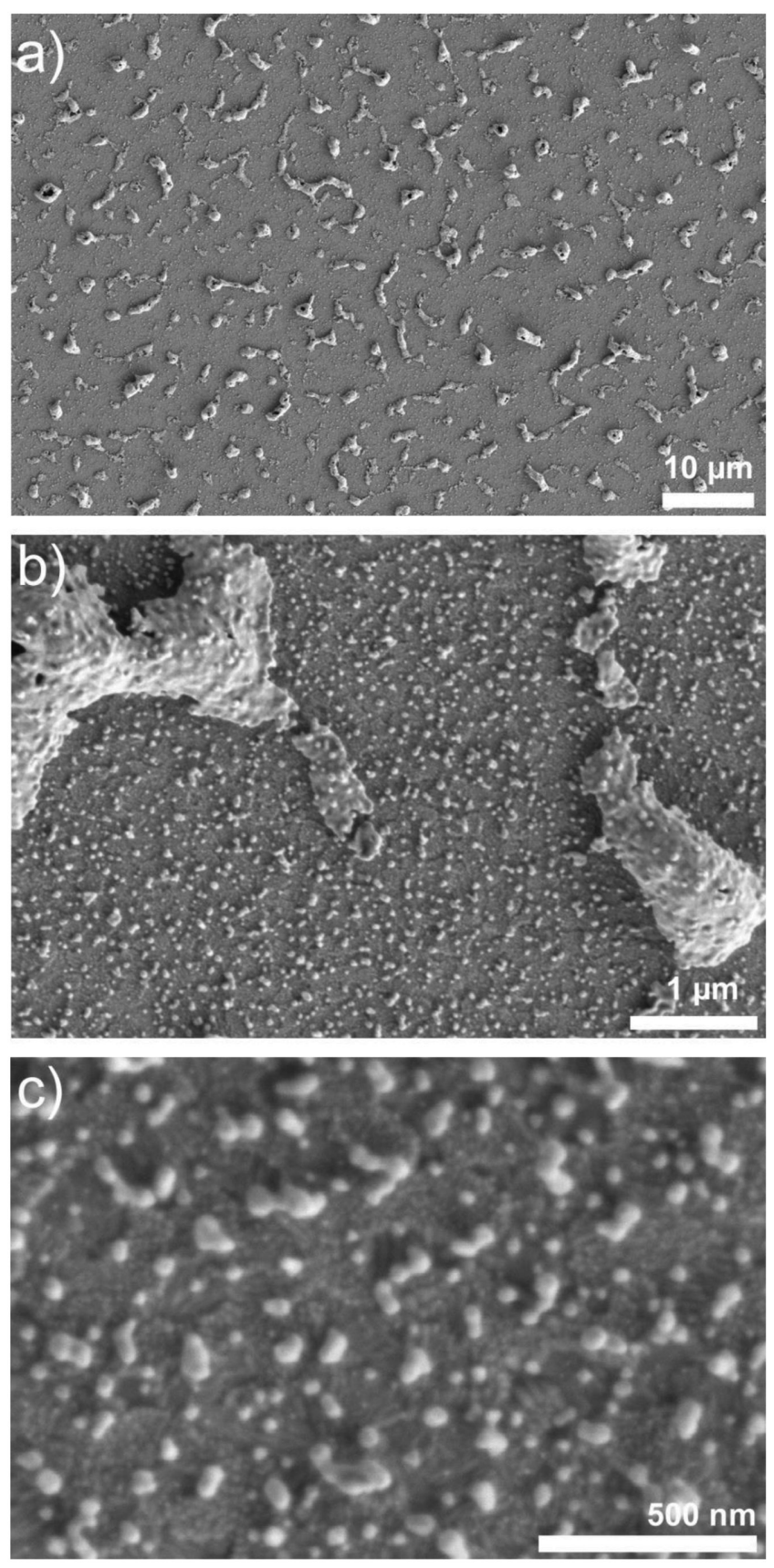

Figure 2. a-c) Scanning electron microscopy images with three magnifications of Pt nanoparticles and their aggregates on ITO glass as obtained after photonic curing.

$1.03 \mu \mathrm{g}_{\mathrm{Pt}} \mathrm{mm}^{-2}$ was sufficient, but a too low coverage (e.g., $0.37 \mu \mathrm{g}_{\mathrm{Pt}} \mathrm{mm}^{-2}$, Figure $4 \mathrm{a}$ ) did not generate enough heat for the thermal decomposition causing just $\mathrm{PtCl}_{x}$ while a too high coverage (e.g., $2.92 \mu \mathrm{g}_{\mathrm{Pt}} \mathrm{mm}^{-2}$, Figure $4 \mathrm{~b}$ ) cracked partially the ITO glass due to the mechanical and thermal stress created during the rapid thermal decomposition and gas evolution (Section SI-11, Supporting Information). Apart from the destructive energy, the higher precursor coverage resulted in similar NP dimensions and NP coverage, but the NP-aggregates became significantly larger compared to the optimum parameters (Figure 4c,d). Another important factor is the shot energy density delivered by the lamp. For instance, a light pulse with just $7.9 \%$ lower short energy density, that is, $(3.24 \pm 0.02) \mathrm{J} \mathrm{cm}^{-2}$ compared to $(3.52 \pm 0.03) \mathrm{J} \mathrm{cm}^{-2}$, resulted in an incomplete precursor conversion indicating an insufficient temperature increase (Figure 4e). This is also reflected by the peak power, which exceeds $12 \mathrm{~kW} \mathrm{~cm}^{-2}$ for the stronger pulse, that is, $(3.52 \pm 0.03) \mathrm{J} \mathrm{cm}^{-2}$, while it is lower than $12 \mathrm{~kW} \mathrm{~cm}$ for the weaker pulse (power vs time plots in Section SI-12, Supporting Information). The bluish color demonstrates clearly the presence of remained chlorides. However, subsequent photonic curing with higher shot energies finalized the conversion.

The Pt/ITO electrodes were further electrochemically characterized in nitrogen-saturated $0.1 \mathrm{M} \mathrm{HClO}_{4}$ using cyclic voltammetry (CV, Figure 5a, Section SI-13, Supporting Information). An insulation layer was printed to define precisely the active Pt electrode area (i.e., $0.84 \mathrm{~mm}^{2}$ ) and to cover the "platinum chloride frame" around the main Pt pattern (vide supra). The typical adsorption and desorption peaks of hydrogen can be seen as well as the formation and dissolution of platinum oxide. The $\mathrm{CV}$ is slightly tilted indicating an $i R$-drop along the electrode surface, which is most likely caused by the resistance of the ITO layer, that is, $12 \Omega \square^{-1}$. The electrochemical surface area (ECSA) of the Pt layer was estimated from the calculated charge in the hydrogen under potential deposition region $Q_{\mathrm{H}, \text { upd }}$. The total charge $Q_{\text {total }}$ for hydrogen adsorption and desorption was determined without considering the double layer charging $Q_{D L}$ according to $Q_{\mathrm{H} \text {,upd }}=0.5 \times\left(Q_{\text {total }}-Q_{\mathrm{DL}}\right)=0.372 \mu \mathrm{C}$. Using a specific charge of $210 \mu \mathrm{C} \mathrm{cm}^{-2}$ ft for a monolayer of clean polycrystalline Pt, the ECSA of the printed and photonic cured Pt can be estimated as $0.177 \mathrm{~mm}^{2}$ Pt. In order to characterize the stability of the Pt electrodes, $7000 \mathrm{CV}$ scans between 0.6 and $1 \mathrm{~V}$ were recorded. The shape of the CV changed only slightly and indicated clearly the continuous presence of the Pt nanostructure.

The stability after long-term cycling for the ORR of the printed Pt/ITO electrode was analyzed in oxygen-saturated $0.1 \mathrm{M}$ $\mathrm{HClO}_{4}$ by using linear sweep voltammetry (LSV, Figure 5b). In fact, the catalytic activity of the Pt NPs and NP aggregates is expected to be controlled by the NP size, mass transport conditions, and shape and by the influence of the thin ITO layer underneath. A complete removal of chloride anions from the printed pattern by the photonic curing process is essential since chloride anions are known to degrade the catalytic activity of Pt. ${ }^{[29]}$ Long-term cycling affected the catalytic activity slightly (half wave potential shifted by $25 \mathrm{mV}$ ) but Pt NPs and NP aggregates stayed intact and attached (Figure 5c,d). Indeed, the Pt electrodes were stable during all electrochemical measurements and cleaning procedures (gas bubbling, washing, and drying under a stream of nitrogen) demonstrating good adhesion and mechanical stability (Section SI-13, Supporting Information). However, it has to be noted that mechanical scratching and tape stripping could remove the particles from the ITO surface. During the voltammetric measurements, the electrode and the solution were resting, which did not provide enough control of the mass transport hindering to extract kinetic data. Further analyses are considered with such printed electrodes as ideal platforms using, for instance, scanning flow cells that have recently been proven to be powerful screening tools with 

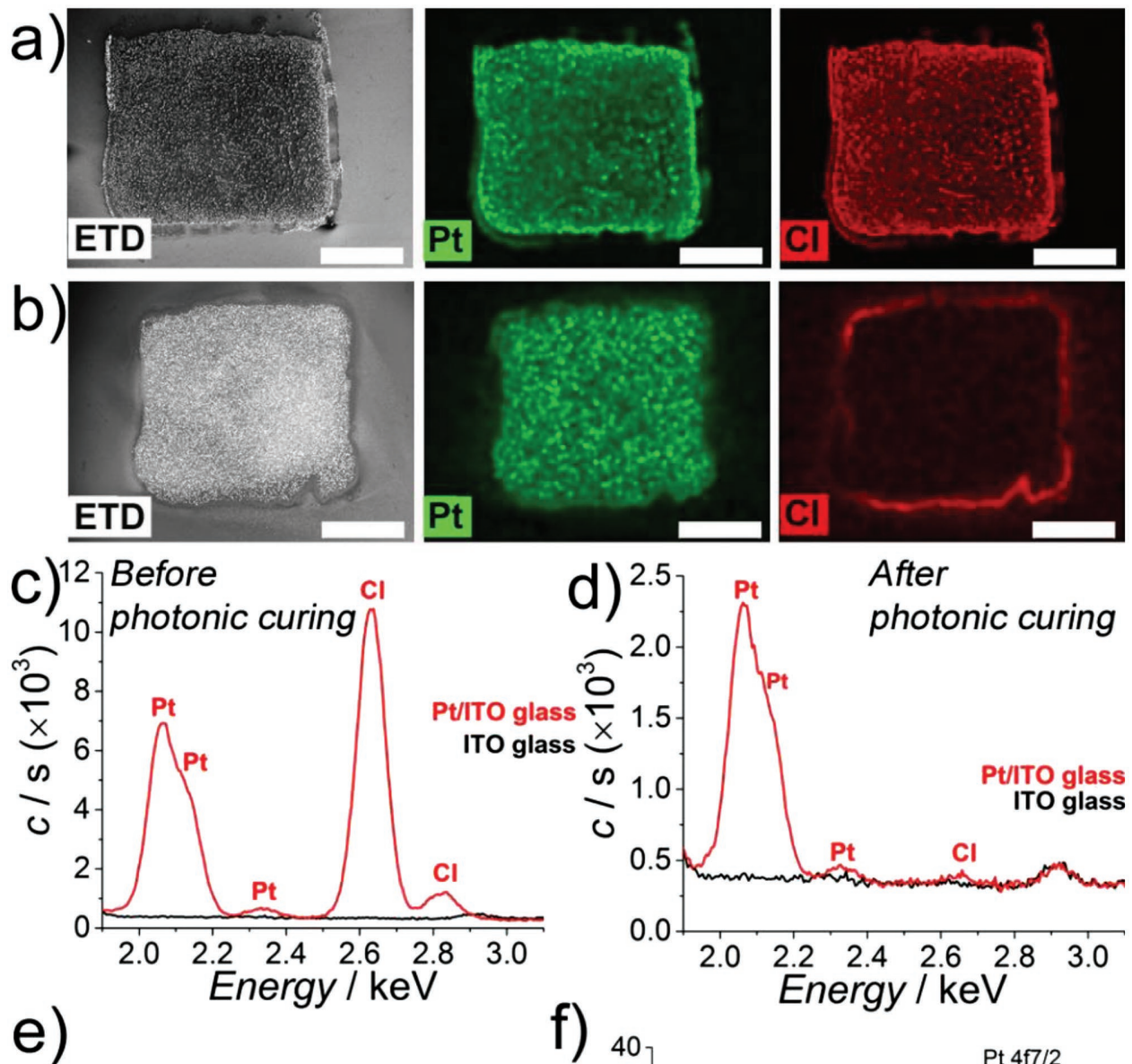

After

photonic curing

e)
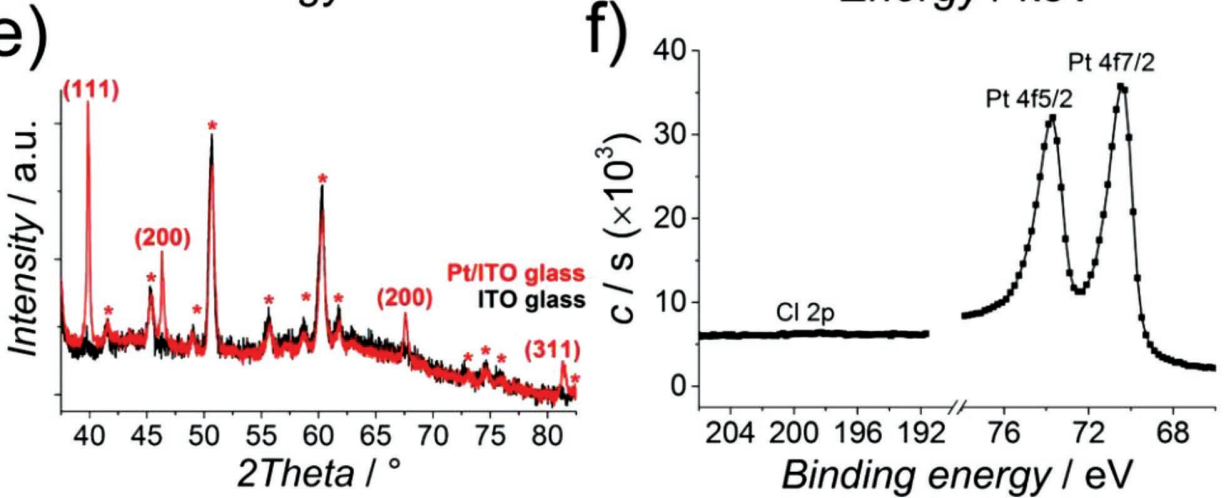

Figure 3. Spectroscopic characterization of Pt precursor and Pt patterns. Scanning electron microscopy-energy dispersive X-ray (SEM-EDX) spectroscopy analysis of inkjet-printed Pt precursor ink a,c) before and b,d) after photonic curing. The scale bar is $400 \mu \mathrm{m}$. Please note that (a) and (b) show two different patterns. Just a narrow ring of chlorine remains around the main Pt pattern due to insufficient light absorption. The ring is formed during ink drying under vacuum as a reverse coffee-ring effect. The main Pt pattern is chlorine free. e) Bragg-Brentano X-ray diffractometry (BBXRD) patterns of bare ITO glass substrate (black) and the Pt NPs on ITO glass (red). Peaks marked with an asterisk correspond to ITO. f) X-ray photoelectron spectroscopy (XPS) spectra of the center of the Pt pattern on the ITO glass substrate focused on $\mathrm{Cl} 2 \mathrm{p}$ and $\mathrm{Pt} 4 \mathrm{f}$ confirm the efficient removal of chlorine and the presence of metallic Pt after photonic curing.

the possibility to extract kinetic data in a similar way as from rotating disk electrode measurements, but with much higher throughput. ${ }^{[30]}$

\section{Conclusion}

Platinum nanoparticles and their micrometer-size aggregates on indium tin oxide electrodes for energy research were fabricated just within few minutes process time under ambient conditions by using a large-scale print-light-synthesis methodology based on a joint inkjet printing and photonic curing platform. The photonic curing process itself took only $330 \mu \mathrm{s}$. A platinum precursor ink containing well-dissolved chloroplatinic acid and ITO substrates was easily and quickly prepared to provide high-printing resolution and fast post-processing thanks to the developed ink formulation, printing parameters, and postprocessing conditions. In fact, adjusting the ink evaporation 

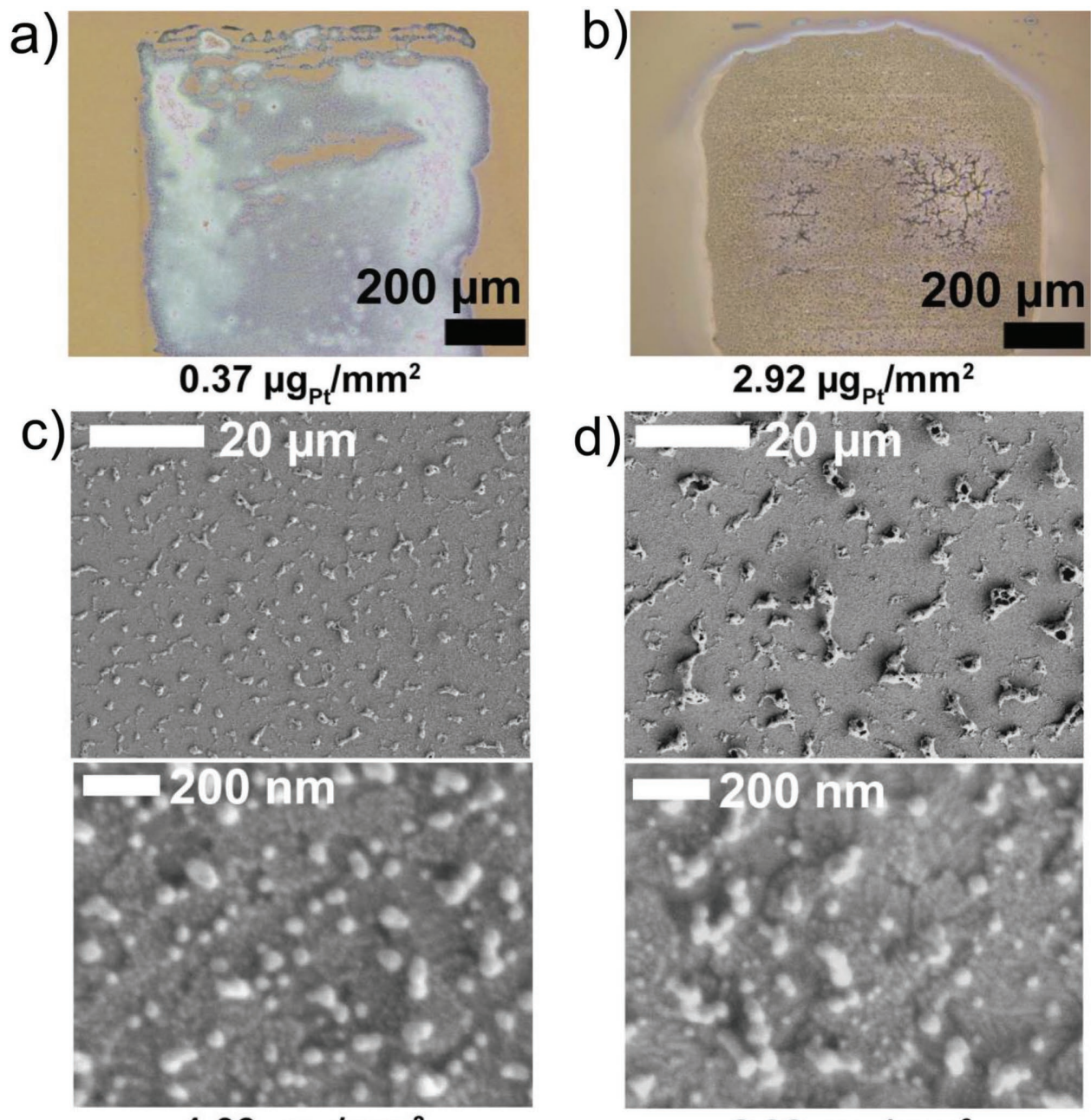

\section{$1.03 \mu \mathrm{g}_{\mathrm{pt}} / \mathrm{mm}^{2}$}

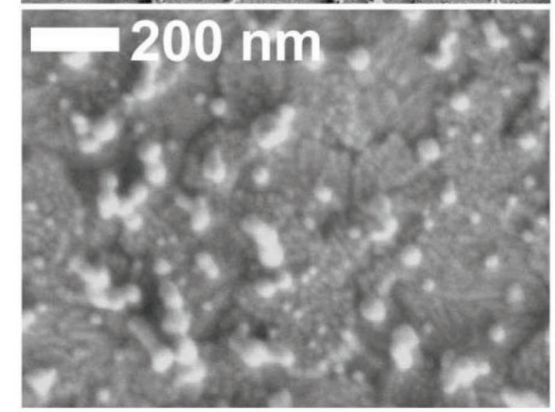

e)

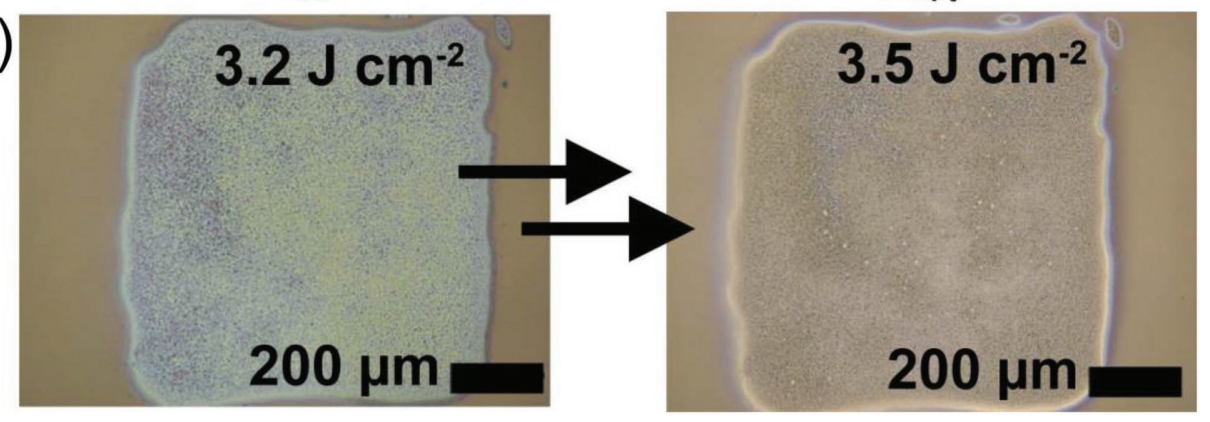

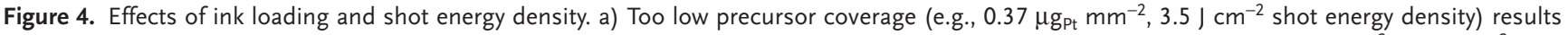
in insufficient temperature increase and incomplete thermal decomposition. b) Too high precursor coverage (e.g., $2.92 \mu \mathrm{g}_{\mathrm{pt}} \mathrm{mm}^{-2}, 3.5 \mathrm{~J} \mathrm{~cm}^{-2}$ shot energy density) causes cracks in the ITO layer due to mechanical and thermal stress created during the rapid thermal decomposition. c) SEM reveals the Pt nanostructures obtained with the optimum parameters $\left(1.03 \mu \mathrm{g}_{\mathrm{Pt}} \mathrm{mm}^{-2}, 3.5 \mathrm{~J} \mathrm{~cm}^{-2}\right.$ shot energy density). d) Higher Pt precursor loadings (e.g., $2.92 \mu \mathrm{g}_{\mathrm{Pt}} \mathrm{mm}^{-2}, 3.5 \mathrm{~J} \mathrm{~cm}^{-2}$ shot energy density) results in larger Pt aggregates, while the NP number and size distribution are comparable. e) Too low shot energy densities (e.g., $3.2 \mathrm{~J} \mathrm{~cm}^{-2}$ ) does not convert the Pt precursor fully into Pt (bluish chloride salts remain), but a subsequent increase of the shot energy density to $3.5 \mathrm{~J} \mathrm{~cm}^{-2}$ gives the same result as flashing directly with the optimized flash light parameters.

rate to provide controlled drying of the printed liquid film, while ensuring on the one hand stable jetting without the risk of dried nozzles and on the other hand high-printing resolution with a good ITO wetting, was of high relevance and achieved by the careful selection of the ink composition, printing parameters, and substrate temperature. Nozzle cleaning was not required while many standard inkjet printing processes require frequent purging procedures to free nozzles from agglomerates that can cause misdirected droplets and nozzle clogging. Hence, the ink volumes used to generate square millimeter-sized patterns with 

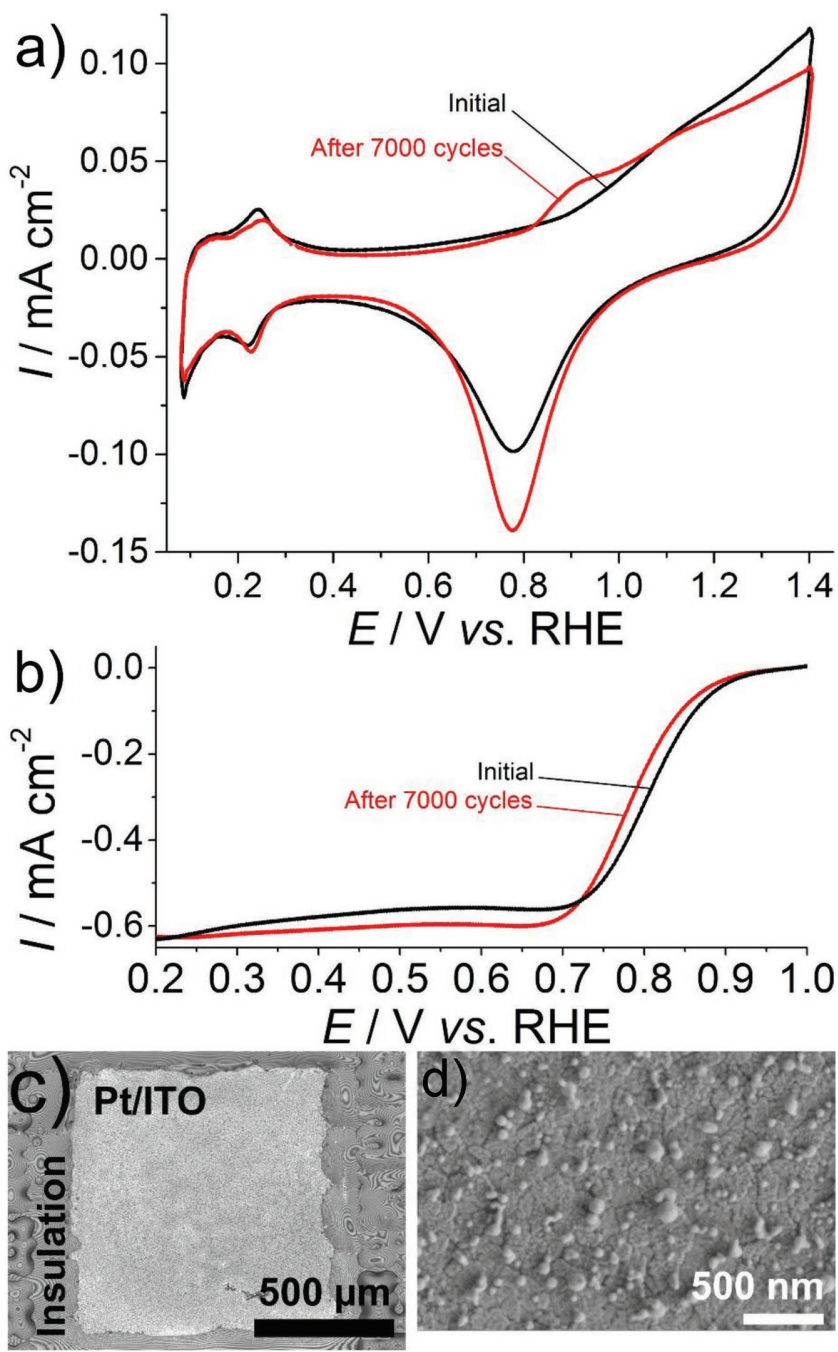

Figure 5. Electrochemical characterization of the activity and stability of the Pt nanostructures on ITO. a) Cyclic voltammograms of Pt/ITO electrodes in nitrogen-saturated $0.1 \mathrm{M} \mathrm{HClO}_{4}$ before (black) and after 7000 scans between 0.6 and $1 \mathrm{~V}, 100 \mathrm{mV} \mathrm{s}^{-1}$ (red), scan rate $100 \mathrm{mV} \mathrm{s}^{-1}$. b) Linear sweep voltammograms of a Pt/ITO electrode in oxygen-saturated $0.1 \mathrm{M} \mathrm{HClO}_{4}$ before and after 7000 scans, scan rate $20 \mathrm{mV} \mathrm{s}^{-1}$. Voltammograms are not $i R$-corrected. c) Laser scanning microscopy image and d) SEM of Pt/ITO electrode after 7000 cycles.

loadings of $\approx 1 \mu \mathrm{g} \mathrm{mm} \mathrm{mm}^{-2}$ platinum were in the lower $\mathrm{nL}$ range forming efficient nanoreactors for the nanoparticle synthesis.

It can be foreseen that digital material ink deposition techniques in combination with advanced post-processing tools, such as flash light induced material transformations, will constantly gain in importance and could influence the way how catalyst layers are being prepared in the future. In particular, the mechanistic investigation of such rapid material conversion processes, which require, for instance, temperature measurements on the microsecond scale, opens further interesting research fields. Currently, the presented procedure is being extended in order to control more precisely particle size, shape, and composition based on ink optimizations, precursor selections, and substrate modifications. The print-light-synthesis approach is suitable to generate $\mathrm{Pt}$ and alloy catalyst libraries that can conveniently be analyzed for their catalytic activity, sensitivity, and stability applying various catalyst screening methodologies. In the future, print-light-synthesis may be applied to printing microporous, 3D catalyst layers of several micrometers in thickness for applications in PEMFCs and electrolyzers through layer-by-layer printing and photonic curing.

\section{Experimental Section}

Materials: Chloroplatinic acid hexahydrate $\left(\mathrm{H}_{2} \mathrm{PtCl}_{6} \cdot \mathrm{xH}_{2} \mathrm{O} ; 38-40 \% \mathrm{Pt}\right.$; 99.9\% Pt; Strem Chemicals), isopropanol, and 1,2-propanediol (Sigma) were of analytical grade and used as received. DI water (18.2 M $\Omega$ ) was produced by using a Milli-Q water purification system with a Q-POD element. ITO $\left(\mathrm{In}_{2} \mathrm{O}_{3} / \mathrm{SnO}_{2}\right)$ coated $1 \mathrm{~mm}$ thick glass slides with measured sheet resistance (Jandel four point probe) of $12 \Omega \square^{-1}$ were used as substrates and obtained from Sigma. As specified by the manufacturer, the thickness of the ITO coating was 120-160 nm and showed a nominal transmittance of $84 \%$ at $550 \mathrm{~nm}$. Furthermore, the composition of the glass was $72.6 \% \mathrm{SiO}_{2}, 0.8 \% \mathrm{~B}_{2} \mathrm{O}_{3}, 1.7 \% \mathrm{Al}_{2} \mathrm{O}_{3}, 4.6 \%$ $\mathrm{CaO}, 3.6 \% \mathrm{MgO}$, and $15.2 \% \mathrm{Na}_{2} \mathrm{O}$ as specified by the manufacturer. The surface tension and viscosity of ink formulations based on mixtures of DI water, isopropanol, and 1,2-propanediol were measured with a Drop Shape Analyzer DSA30S (Krüss) and Viscometer SV-1A series viscometer (A\&D Instruments Ltd.). All inks, substrates, and printed layers were prepared and stored under ambient conditions.

Fabrication of Pt Nanostructures on ITO Glass: An X-Serie CeraPrinter (Ceradrop, France) was used to print patterns of the Pt precursor ink with disposable Fujifilm Dimatix, piezoelectric-based cartridges DMC-11610 with 16 individually addressable nozzles and $10 \mathrm{pL}$ nominal droplet volume. The machine operates in a closed environment with extraction system. The ITO glass substrates were pre-treated in isopropanol in order to ensure a surface free energy higher than the surface tension of the Pt precursor ink for an improved wetting (small contact angle). All printing parameters, such as jetting frequency, waveform shape for the piezoelectric actuation, and lateral overlapping of adjacent droplets on the substrate, were adjusted for optimum printing resolution. The substrate plate was heated to an effective temperature of $54{ }^{\circ} \mathrm{C}$. Photonic curing of the printed patterns was performed with a PulseForge 1300 system (Novacentrix, USA) that was fully integrated into the CeraPrinter. A single pulse of $330 \mu$ s duration was applied to each sample placed under the Xe lamp. The energy was adjusted by controlling the lamp driver charging voltage, which were $765 \mathrm{~V}$ or lower in this work. The resulting shot energy density of the emitted light was determined using a BX-100 Bolometer (Novacentrix, USA) that was placed on the substrate plate of the printer device where the distance of Bolometer surface to the Xe flash lamp was identical to the one of the printing substrates. Ten identical pulses with a temporal separation of $7.5 \mathrm{~s}$ (i.e., $0.133 \mathrm{~Hz}$ ) were recorded and the measured shot energies averaged. The initial bolometer temperature was set to $30^{\circ} \mathrm{C}$ and special care was taken that its temperature did not exceed $60{ }^{\circ} \mathrm{C}$ during the measurements, which could result in inaccurate values for the shot energy.

Electrode Characterization: The Pt/ITO patterns were characterized by using a Keyence VK-8700 laser scanning microscope, Fei Teneo scanning electron microscope with EDX spectroscopy (XFlash Silicon drift detector), a Bruker D8 Advance XRD using the CuK $\alpha$ emission profile, and XPS using a monochromatic Al K $\alpha$ X-ray source of $24.1 \mathrm{~W}$ power with a beam size of $100 \mu \mathrm{m}$ directed into the center of $1 \mathrm{~mm}^{2}$ printed squares. The spherical capacitor analyzer was set at $45^{\circ}$ take-off angle with respect to the sample surface. The pass energy was $46.95 \mathrm{eV}$ yielding a full width at half maximum of $0.91 \mathrm{eV}$ for the $\mathrm{Ag} 3 \mathrm{~d} 5 / 2$ peak.

The electrochemical characterization was performed with an Autolab PGSTAT302N with FRA32M module using a stationary sample in resting solution. The electrodes were taken from the printer and assembled on the bottom of an electrochemical cell that could be purged either with nitrogen or oxygen to carry out measurements in de-aerated and oxygenated conditions, respectively. $\mathrm{An} \mathrm{Ag} / \mathrm{AgCl} / 1 \mathrm{M} \mathrm{KCl}$ 
reference electrode and a platinized niobium mesh served as reference and counter electrodes, respectively, comprising the three-electrode arrangement. The potential of the reference electrode was calibrated before each experiment using a reversible hydrogen electrode (RHE, HydroFlex, gaskatel). While not measuring, the Pt electrode was left at the open-circuit potential. $0.1 \mathrm{M} \mathrm{HClO}_{4}$ was freshly prepared and the $\mathrm{pH}$ value $(\mathrm{pH}=1.00)$ accurately checked. Nitrogen or oxygen was bubbled into the solution for at least $30 \mathrm{~min}$ before the electrochemical measurements were performed. $50 \mathrm{CVs}$ in nitrogen-saturated $0.1 \mathrm{M}$ $\mathrm{HClO}_{4}$ were recorded with an upper vertex potential of $1.41 \mathrm{~V}$ for preconditioning. ${ }^{[31]}$ The last complete cycles were taken for the CV plots. Before the ORR measurements, $16 \mathrm{CV}$ cycles during oxygen bubbling were run at $100 \mathrm{mV} \mathrm{s}^{-1}$ with vertex potentials 0.08 and $1.56 \mathrm{~V}$ versus RHE in order to provide sufficient preconditioning and cleaning of the electrocatalyst surface. Directly after, the oxygen bubbling was interrupted and the Pt electrode kept at $0.16 \mathrm{~V}$ for $60 \mathrm{~s}$ before a forward and reverse sweep was recorded (start potential $0.16 \mathrm{~V}$, vertex potential $1 \mathrm{~V}$, scan rate $20 \mathrm{mV} \mathrm{s}^{-1}$ )

\section{Supporting Information}

Supporting Information is available from the Wiley Online Library or from the author.

\section{Acknowledgements}

This work was financially supported by the Swiss National Science Foundation (SNSF Ambizione Energy Project No. 154297). Prof. Hubert $\mathrm{H}$. Girault (EPFL LEPA) is acknowledged for hosting the SNSF project and giving full access to his laboratory facilities. The support from Victor Costa Bassetto (EPFL LEPA) is acknowledged. Pierre Mettraux (EPFL STI MHMC MHMC-GE) and Dr. Pascal Schouwink (EPFL ISIC-GE-VS) are thanked for performing the XPS and XRD measurements, respectively. Rob Hendriks from Novacentrix is greatly thanked for his support on the PulseForge 1300 system and for providing the Xe flash lamp emission spectrum.

\section{Conflict of Interest}

The authors declare no conflict of interest.

\section{Keywords}

electrocatalysis, inkjet printing, nanoparticles, photonic curing, platinum

Received: July 28, 2017

Revised: October 8, 2017

Published online: December 4, 2017

[1] a) Y. Wang, K. S. Chen, J. Mishler, S. C. Cho, X. C. Adroher, Appl. Energy 2011, 88, 981; b) M. Carmo, D. L. Fritz, J. Mergel, D. Stolten, Int. J. Hydrogen Energy 2013, 38, 4901.

[2] a) I. Katsounaros, S. Cherevko, A. R. Zeradjanin, K. J. J. Mayrhofer, Angew. Chem., Int. Ed. 2014, 53, 102; b) Y. Zheng, Y. Jiao, M. Jaroniec, S. Z. Qiao, Angew. Chem., Int. Ed. 2015, 54, 52; c) P. C. K. Vesborg, B. Seger, I. Chorkendorff, J. Phys. Chem. Lett. 2015, 6, 951; d) M. Shao, Q. Chang, J. P. Dodelet, R. Chenitz, Chem. Rev. 2016, 116, 3594; e) J. Zheng, W. Sheng, Z. Zhuang, B. Xu, Y. Yan, Sci. Adv. 2016, 2, e1501602.

[3] a) K.-S. Lee, I.-S. Park, Y.-H. Cho, D.-S. Jung, N. Jung, H.-Y. Park, Y.-E. Sung, J. Catal. 2008, 258, 143; b) Y. Liu, W. E. Mustain,
J. Am. Chem. Soc. 2013, 135, 530; c) L. Zhao, Z. B. Wang, J. Liu, J. J. Zhang, X. L. Sui, L. M. Zhang, D. M. Gu, J. Power Sources 2015, 279, 210; d) Y. J. Wang, B. Fang, H. Li, X. T. Bi, H. Wang, Prog. Mater. Sci. 2016, 82, 445; e) H. Lv, D. Li, D. Strmcnik, A. P. Paulikas, N. M. Markovic, V. R. Stamenkovic, Nano Energy 2016, 29, 149; f) C. Jackson, G. T. Smith, D. W. Inwood, A. S. Leach, P. S. Whalley, M. Callisti, T. Polcar, A. E. Russell, P. Levecque, D. Kramer, Nat. Commun. 2017, 8, 15802.

[4] a) A. Chen, P. Holt-Hindle, Chem. Rev. 2010, 110, 3767; b) P. Liu, Y. Zhao, R. Qin, S. Mo, G. Chen, L. Gu, D. M. Chevrier, P. Zhang, Q. Guo, D. Zang, B. Wu, G. Fu, N. Zheng, Science 2016, 352, 797.

[5] a) J. Zhang, M. B. Vukmirovic, Y. Xu, M. Mavrikakis, R. R. Adzic, Angew. Chem., Int. Ed. 2005, 44, 2132; b) V. Stamenkovic, B. S. Mun, K. J. J. Mayrhofer, P. N. Ross, N. M. Markovic, J. Rossmeisl, J. Greeley, J. K. Nørskov, Angew. Chem., Int. Ed. 2006, 45, 2897; c) S. Guo, S. Zhang, S. Sun, Angew. Chem., Int. Ed. 2013, 52, 8526; d) Y. Kang, P. Yang, N. M. Markovic, V. R. Stamenkovic, Nano Today 2016, 11, 587; e) Z. W. She, J. Kibsgaard, C. F. Dickens, I. Chorkendorff, J. K. Nørskov, T. F. Jaramillo, Science 2017, 355, eaad4998.

[6] R. Alink, M. Schüßler, M. Pospischil, D. Erath, D. Gerteisen, J. Power Sources 2016, 327, 526.

[7] B. Martinez-Vazquez, D. G. Sanchez, J. L. Castillo, K. A. Friedrich, P. L. Garcia-Ybarra, Int. J. Hydrogen Energy 2015, 40, 5384.

[8] a) P. Calvert, Chem. Mater. 2001, 13, 3299; b) L. J. Deiner, T. L. Reitz, Adv. Eng. Mater. 2017, 19, 1600878; c) G. Mattana, A. Loi, M. Woytasik, M. Barbaro, V. Noël, B. Piro, Adv. Mater. Technol. 2017, 10, 1700063, http://onlinelibrary.wiley.com/doi/10.1002/ adem.201600878/abstract.

[9] a) D. Li, D. Sutton, A. Burgess, D. Graham, P. D. Calvert, J. Mater. Chem. 2009, 19, 3719; b) B. Bao, M. Li, Y. Li, J. Jiang, Z. Gu, X. Zhang, L. Jiang, Y. Song, Small 2015, 11, 1649; c) C. Gadea, D. Marani, V. Esposito, J. Phys. Chem. Solids 2017, 101, 10.

[10] a) A. Lesch, F. Cortés-Salazar, V. Amstutz, P. Tacchini, H. H. Girault, Anal. Chem. 2015, 87, 1026; b) M. Jović, Y. Zhu, A. Lesch, A. Bondarenko, F. Cortés-Salazar, F. Gumy, H. H. Girault, J. Electroanal. Chem. 2017, 786, 69.

[11] a) M. S. Saha, D. Malevich, E. Halliop, J. G. Pharoah, B. A. Peppley, K. Karan, J. Electrochem. Soc. 2011, 158, B562; b) S. Shukla, K. Domican, K. Karan, S. Bhattacharjee, M. Secanell, Electrochim. Acta 2015, 156, 289; c) A. Lesch, F. Cortés-Salazar, V. Costa Bassetto, V. Amstutz, H. H. Girault, Chimia 2015, 69, 284.

[12] Z. Wang, Y. Nagao, Electrochim. Acta 2014, 129, 343.

[13] a) E. Reddington, A. Sapienza, B. Gurau, R. Viswanathan, S. Sarangapani, E. S. Smotkin, T. E. Mallouk, Science 1998, 280, 1735; b) X. Liu, Y. Shen, R. Yang, S. Zou, X. Ji, L. Shi, Y. Zhang, D. Liu, L. Xiao, X. Zheng, S. Li, J. Fan, G. D. Stucky, Nano Lett. 2012, 12, 5733; c) J. P. Grote, A. R. Zeradjanin, S. Cherevko, K. J. J. Mayrhofer, Rev. Sci. Instrum. 2014, 85, 104101; d) P. F. Newhouse, B. A. Parkinson, J. Mater. Chem. A 2015, 3, 5901; e) A. Shinde, D. Guevarra, J. A. Haber, J. Jin, J. M. Gregoire, J. Mater. Res 2015, 30, 442.

[14] a) K. A. Schroder, S. C. McCool, W. F. Furlan, in 2006 NSTI Nanotechnology Conf. Trade Show - NSTI Nanotechnology 2006 Technical Proc., Boston, MA: U S Vol. 3, 2006, pp. 198-201; b) C. J. Stolle, T. B. Harvey, D. R. Pernik, J. I. Hibbert, J. Du, D. J. Rhee, V. A. Akhavan, R. D. Schaller, B. A. Korgel, J. Phys. Chem. Lett. 2014, 5, 304; c) K. Jang, S. Yu, S. H. Park, H. S. Kim, H. Ahn, J. Alloys Compd. 2014, 618, 227; d) S. Das, B. Yang, G. Gu, P. C. Joshi, I. N. Ivanov, C. M. Rouleau, T. Aytug, D. B. Geohegan, K. Xiao, ACS Photonics 2015, 2, 680; e) H.-W. Cui, J.-T. Jiu, S. Nagao, T. Sugahara, K. Suganuma, H. Uchida, K. A. Schroder, RSC Adv. 2014, 4, 15914.

[15] a) Y. S. Rosen, A. Yakushenko, A. Offenhausser, S. Magdassi, ACS Omega 2017, 2, 573; b) W. H. Chung, H. J. Hwang, H. S. Kim, Thin Solid Films 2015, 580, 61. 
[16] C. Yim, A. Sandwell, S. S. Park, ACS Appl. Mater. Interfaces 2016, 8, 22369.

[17] a) S. H. Park, H. S. Kim, J. Electrochem. Soc. 2015, 162, F204 b) S. Lee, S.-H. Park, K. Jang, S. Yu, C. Song, H.-S. Kim, H. Ahn, J. Alloys Compd. 2017, 724, 684.

[18] a) J. Liu, C. Zhong, X. Du, Y. Wu, P. Xu, J. Liu, W. Hu, Electrochim. Acta 2013, 100, 164; b) S. Li, H. Chen, J. Liu, Y. Deng, X. Han, W. Hu, C. Zhong, ACS Appl. Mater. Interfaces 2017, 9, 27765.

[19] a) X. Chen, A. Balouch, A. Ali Umar, M. Mat Salleh, M. Oyama, J. Electroanal. Chem. 2016, 779, 156; b) J. C. M. Silva, R. M. Piasentin, E. V. Spinacé, A. O. Neto, E. A. Baranova, Mater. Chem. Phys. 2016, 180, 97.

[20] a) A. Von Weber, E. T. Baxter, H. S. White, S. L. Anderson, J. Phys. Chem. C 2015, 119, 11160; b) D. Lotti, P. Hamm, J. P. Kraack, J. Phys. Chem. C 2016, 120, 2883.

[21] a) H. Chhina, S. Campbell, O. Kesler, J. Power Sources 2006, 161,893 ; b) A. Balouch, A. A. Umar, S. T. Tan, S. Nafisah, S. K. Md Saad, M. M. Salleh, M. Oyama, RSC Adv. 2013, 3, 19789.

[22] S. Zhao, A. E. Wangstrom, Y. Liu, W. A. Rigdon, W. E. Mustain, Electrochim. Acta 2015, 157, 175.
[23] C. D. O'Connell, M. J. Higgins, R. P. Sullivan, S. S. Jamali, S. E. Moulton, G. G. Wallace, Nanotechnology 2013, 24, 505301.

[24] N. Papageorgiou, W. F. Maier, M. Grätzel, J. Electrochem. Soc. 1997, $144,876$.

[25] B. Derby, Annu. Rev. Mater. Res. 2010, 40, 395

[26] a) J. O. Hernandez, E. A. Choren, Thermochim. Acta 1983, 71, 265; b) A. E. Schweizer, G. T. Kerr, Inorg. Chem. 1978, 17, 2326.

[27] a) M. Harada, H. Einaga, Langmuir 2006, 22, 2371; b) S. Chen, Q. Yang, H. Wang, S. Zhang, J. Li, Y. Wang, W. Chu, Q. Ye, L. Song, Nano Lett. 2015, 15, 5961.

[28] J. F. Moulder, W. F. Stickle, P. E. Sobol, K. D. Bomben, Handbook of X-Ray Photoelectron Spectroscopy, Physical Electronics, Inc., Eden Prairie, MN 1995.

[29] T. J. Schmidt, U. A. Paulus, H. A. Gasteiger, R. J. Behm, J. Electroanal. Chem. 2001, 508, 41.

[30] a) N. Kulyk, S. Cherevko, M. Auinger, C. Laska, K. J. J. Mayrhofer, J. Electrochem. Soc. 2015, 162, H860; b) S. A. Tschupp, S. E. Temmel, N. P. Salguero, J. Herranz, T. J. Schmidt, J. Electrochem. Soc. 2017, 164, E3448.

[31] K. Shinozaki, J. W. Zack, R. M. Richards, B. S. Pivovar, S. S. Kocha, J. Electrochem. Soc. 2015, 162, F1144. 